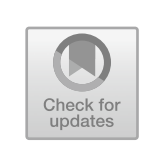

CHAPTER 8

\title{
Accidents, Injuries, Escapes and Suicides
}

\section{Introduction: A Culture of Kindness or Harm?}

"The asylum exists for the benefit of the patients" Charles Mercier reminded staff when he summarised the approach they needed to take: to be kind, courteous, sympathetic, tactful, and not overbearing or bullying; to "cheer the unhappy", "soothe the excited" and "make peace between the quarrelsome". ${ }^{1}$ Staff must never threaten, tease or frighten, mock, jeer, insult, disparage or deceive a patient, lose one's temper with or strike a patient or punish one in any way. ${ }^{2}$ Mercier spelled this out because he was aware of harsh practices. He instructed staff (bold in the original), that: "under no circumstances whatever should a patient be knelt on. More broken ribs and broken breastbones are due to this practice than to all other circumstances put together". ${ }^{3}$ Staff struck patients, but according to one wartime staff member, "the attendant who knows his business seldom leaves a mark on the patient he abuses", a state of affairs also referred to by Louise Hide in her study of late-Victorian and Edwardian asylums. ${ }^{4}$ One former patient reported that when he dared to criticise his attendants, they punished him with concealable torments, including giving him strong laxatives, placing a live earwig in his porridge and heavily over-salting his soup then laughing when he spat it out. ${ }^{5}$ Another former patient who became an attendant, described his colleagues as unsympathetic and harsh. He noted their abusive language, which he attributed to them being "under the delusion that almost

(C) The Author(s) 2021

C. Hilton, Civilian Lunatic Asylums During the First World War, Mental Health in Historical Perspective, https://doi.org/10.1007/978-3-030-54871-1_8 
everything in the universe was composed of blood", repeatedly using a word "which rhymes with ruddy": "You have read of Moses and the old time necromancers of Egypt turning water into blood. They could turn everything into blood."6

Rachel Grant-Smith wrote about her experiences as an asylum patient. She alleged brutality and degrading nursing practices. She described being "forced" to take laxatives, for her "bad behaviour", and unless she cooperated "it meant my being forcibly laid down and three or four nurses pulling my mouth open and pouring it down." 7 She observed distressing scenes:

Fanny Black and Miss Hurd were made to sit out of bed on the chamber utensil many hours in the night, quite naked, often for an hour at a time. Miss Hurd has lately died from consumption. A young nurse, named Green, promised me, after I had spoken to her about ill-treating patients, that she would not do it again, and subsequently told me that she would get into trouble for not kicking a patient, Mrs. Beverley, to keep her quiet when told by Nurse Rooke to do so. ${ }^{8}$

The British periodical Truth published a summary of Grant-Smith's report in July 1914. ${ }^{9}$ Conveniently for the authorities, it disappeared from the public agenda when national priorities supervened.

The terms "rough handling" and "rough usage" appeared frequently in minutes and reports of the asylums' Board of Control ("the Board"). ${ }^{10}$ However, with reports from staff and patients usually given credence in a hierarchical fashion, if a patient alleged rough handling and a staff member denied it, the patient was rarely believed. ${ }^{11}$ Staff expected each other to conform to their unwritten peer group rules of loyalty to colleagues, which included collusion in the event of a complaint. Inconsistencies in reports between patients and staff, and often agreement between ward staff of the same grade, suggest that loyalty to colleagues took precedence over patients' wellbeing. ${ }^{12}$ Some of these issues, and some others, are illustrated by an incident in the life of Edith B, a 42year-old schoolteacher admitted to Colney Hatch in 1913 (Fig. 8.1). ${ }^{13}$ Edith had a psychotic illness and her "certified cause of insanity" was "religious mania". ${ }^{14}$ In July 1915, her doctor wrote: 
Fig. 8.1 Edith B, soon

after admission

(Photographs of female patients at Colney

Hatch $1908-1918$

$\mathrm{H} 12 / \mathrm{CH} / \mathrm{B} / 18 / 003$

LMA)

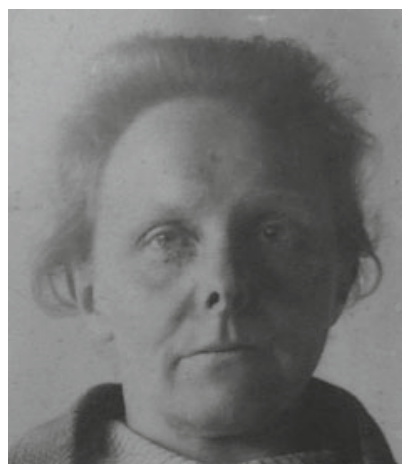

She is very grandiose and exalted and believes that she is the Virgin Mary and that the archangel has visited her and greeted her with "Hail, Mary, full of grace." She states that she had a child afterwards. She is excitable, garrulous and spiteful and entirely irrelevant in conversation. She is in fair health.

Sometimes she "could feel the Holy Child leave her womb." Edith's clinical notes recorded ups and downs. Occasionally they mentioned injuries, allegedly inflicted by other patients, on one occasion a black-eye, and on another, cuts which required stitching. Later she had scabies, a skin condition associated with an unhygienic environment. Her delusions persisted, and she gradually became "demented, solitary, unemployable." 15

In 1916, Edith reported that Nurse $H$ hit her. Edith had a bruised face. Clear that something had happened, the visiting committee (VC) investigated. The nurse denied hitting Edith but admitted to pushing her in the lavatories (a common location for displays of anger, out of sight of others $^{16}$ ) and Edith hit her face on one of the partitions. Nurse $\mathrm{H}$ apologised and said that she "did not mean to be rough". Nurse K, a more senior staff member, witnessed the incident, and gave another account, that Nurse $\mathrm{H}$ took hold of Edith by her neck in a very rough manner but did not strike her. Each person told a different story.

The VC insisted that Nurse $\mathrm{H}$ resign although it could have dismissed her. ${ }^{17}$ Resignation was less harsh than dismissal. It was less damaging to her reputation if she sought another job, and it did not entail her forfeiting her superannuation contributions. The minutes did not mention her previous work record and her apology appears to have been 
taken as an admission of guilt rather than an indication of remorse. The same VC adjudicated over allegations about another nurse in similar circumstances a few months later. In that case, the VC cautioned her as they were sure that she "had no intention of being unkind to the patients but that she must, in future, on such occasions be most careful in handling the patients". ${ }^{18}$ The VCs' inconsistency in dealing with misdemeanours contributed to staff insecurity and their lack of trust in the leadership. ${ }^{19}$

Edith's story demonstrates some of the challenges faced by asylum authorities when trying to deal with untoward incidents, whether "accidents" or injuries, escapes or suicides. This chapter aims to bring together components of asylum life-the patients, senior and junior staff, the public, the law, the Board and the VCs- to create a broad picture about what happened when things went wrong. There are drawbacks, in that much of the material is necessarily anecdotal with inconsistencies and contradictions. However, cases provide enough evidence to identify patterns of attitudes, behaviours and decision making, from which conclusions can be drawn.

\section{Abuse in the Asylums: Allegations and Outcomes}

Most VC members had no specific training to help them evaluate allegations of abuse or maltreatment, although a few could draw upon their experience as magistrates. The VCs were often bewildered by inconsistent, contradictory and vague evidence, particularly from patients who changed their original statements. ${ }^{20}$ They attributed this inconsistency to their mental disturbance being all-encompassing, a medically acceptable perspective. According to Mercier, "they are out of their minds and not responsible for what they do or say", even when their delusions and hallucinations were unrelated to the subject in hand. ${ }^{21}$ Allegations made on their behalf by relatives or friends were considered similarly contaminated because of their source.

Evidence has not come to light that VCs or superintendents raised the possibility that inconsistent reports from patients were associated with them fearing repercussions from the staff they accused. Indications that this happened include a newspaper report, some years before the war, about the inquest into the death of Charles Andrews who sustained rib fractures while a patient at Colney Hatch. It stated that he had told his wife that he "had 'been knocked about' for an act which he could not 
help, but he would not tell her by whom" suggesting that he feared retribution if he exposed maltreatment by staff. ${ }^{22}$ Patients' fear was also likely to have been a factor in the VC's investigations into allegations that Attendant Frampton indecently assaulted young male patients in his charge. The patients had to give evidence in front of the accused. Evidence was conflicting, with some allegations "forgotten". The confusing picture led the VC to conclude that the allegations were false. ${ }^{23}$ Shortly after, Frampton was arrested and charged with indecent exposure to some boys in Finsbury Park. The similarities between the behaviours supported the reality of the patient' allegations, but only then was Frampton dismissed from asylum employment. Scandalous allegations by patients, especially when accompanied by contradictory evidence, were particularly unlikely to be believed. ${ }^{24}$

Staff as well as patients might "forget" incidents. When allegations arose about Attendant Orton hitting and injuring a patient, both parties "forgot" what happened. Orton absconded from Colney Hatch, resulting in automatic dismissal and forfeit of his superannuation contributions. ${ }^{25}$ Police traced him to Portsmouth, with the result that the asylum wrote to him about their concerns: the return of his uniform and keys. Nothing further was heard from him until he reappeared at Colney Hatch, seeking repayment of his superannuation. He maintained that he had no memory of any misdemeanours. ${ }^{26}$ Sir John Collie, medical examiner for the London County Council (LCC) and author of a book on malingering, examined Orton and declared his memory loss genuine, thus salvaging the superannuation. ${ }^{27}$ Other incidents did not end so well for the alleged perpetrator.

In addition to patients' words lacking credibility, so too did those of junior staff who were placed only just above patients in the asylum hierarchy. In consequence, after an untoward event, juniors were more likely to be disciplined than the seniors under whom they worked. This can be illustrated by the events around Mrs. I, a patient at Colney Hatch who was "under continuous observation because of suicidal tendencies." A probationer nurse, new to the ward that morning, was delegated to look after Mrs. I when the ward's qualified staff went to breakfast, but Mrs. I managed to break the glass door of a medicine cupboard and took a fatal dose of camphor. At the investigation, the qualified staff said they had told the new nurse specifically to look after Mrs. I, although there were no witnesses to that from outside their circle. The asylum informed the Board, which concluded that the new nurse was "careless and incapable", 
and recommended to the VC that it "terminated her engagement." 28 There is no record about whether the Board questioned the appropriateness of the established staff in delegating responsibility to a probationer, or what they actually told her about Mrs. I. Staff closed ranks, and the words of those more senior prevailed, as if trustworthiness and judgement automatically increased with status.

Asylums provided different degrees of detail about their investigations into untoward events. However, minutes hint at clandestineness, such as when the VC at Colney Hatch decided to inform the Board about an incident only if asked directly. If that happened, it would report that the asylum had dispensed with the nurse's services, and "as all the corroborative evidence has been by patients, it is doubtful whether a conviction would be obtained." 29 Despite the recurring pattern of institutional secrecy in some cases of ill treatment, "wilful neglect" or allowing a patient to escape sometimes prompted the Board to contact the Director of Public Prosecutions. ${ }^{30}$ Penalties for a member of staff found guilty of a misdemeanour under the Lunacy Act 1890 included imprisonment or a fine of up to $£ 20 .{ }^{31}$ This was a hefty punishment considering that a ward attendant's salary (after deductions for uniform and "living in") was under $£ 40$ a year. ${ }^{32}$ If a case went to court, publicity was almost inevitable, risking criticism about the asylum and its leadership and creating a "blot on the copy book for what the asylums sought to provide". 33 Mercier emphasised that a lapse in staff vigilance could result in "catastrophe": injury or death to those under their care, and disaster to their own career. ${ }^{34}$ For many male staff who lived in tied cottages with their families this was a huge concern, as dismissal or imprisonment would also wreck the lives of their family. Fear of the consequences probably contributed to staff perpetuating cultures of secrecy and dishonesty. ${ }^{35}$

Another mechanism of concealment occurred after altercations when attendants failed to follow instructions to "report the occurrence immediately to the Medical Officer" even if "in the attendant's own opinion no injury had been caused to the patient." 36 Sometimes in these circumstances the patient died, the injury being more serious than the attendant surmised. A doctor's examination of the patient soon after an incident could help clarify the course of events. The patient's words might be believed if they were compatible with the clinical findings, and while superficial injury such as red marks, bruises or scratches were still in evidence, they could indicate the recent timing of the injury. Without that early assessment, possibly fatal internal injuries identified later were 
unlikely to be attributed to a particular attendant or shift, providing a degree of immunity for the perpetrator.

Despite secrecy around episodes of rough handling, patients could be remarkably up to date with asylum news which might then spread further afield, creating gossip and disrepute about the asylum and its leadership. ${ }^{37}$ Short visiting times, ward staff reading patients' out-going letters, and most new junior staff being required to live-in helped guard against this. In addition, with time, both patients and staff could become institutionalised, moulded into the system and minimising protest, although, unlike the patients, staff who were uncomfortable with the regime were free to leave. Occasionally someone contacted an external body, placing an asylum's reputation on a knife edge of publicity, as at Colney Hatch in the case of a 33-year-old Spanish patient, Juan R, recorded as dying from "rupture of intestine caused by falling against a table." 38 Officially categorised as an accident, this seems an unlikely explanation since, in a fall, reflex contraction of powerful abdominal muscles would help protect internal organs from blunt trauma, a matter learnt, if not in anatomy classes at medical school, then on the sports field. There was no mention of loss of consciousness preceding the injury, which might have prevented reflex muscle action. If the patient had lost consciousness, the alleged perpetrators would probably have mentioned it in their defence. A patient-witness stated that two attendants had treated Juan roughly, but the attendants denied it, and staff words over-rode those of patients. However, someone wrote to the Spanish Consul General, asserting that a Spanish patient had been murdered in the asylum, prompting the consul to contact the asylum. The VC minutes only tell us that the medical superintendent was due to meet the consul, and in common with documentation of other complaints, they lack detail of the discussion and outcome. ${ }^{39}$ It is likely that the superintendent reassured the consul that patients' were unreliable witnesses and that his attendants were, in words similar to those of the Board, "as humane and deserving a body of workers as can be found". 40

In contrast to assumptions that staff were humane, patients were assumed to be irresponsible, untrustworthy and sometimes dangerous, requiring stringent safety precautions. Some precautions were obvious, such as ensuring the safe keeping of brooms, broken chairs, fire pokers and roller towels which could be used as weapons against self or others. ${ }^{41}$ Others limited the freedom of patients, many of whom did not require the measures but were subject to them nevertheless. They could be 
condescending, such as routinely counting patients in and out when being escorted between ward and work-place. ${ }^{42}$ The value of others which were demeaning were debated, such as staff searching patients' clothes every night to check for concealed home-made weapons, perhaps a stone or other hard object in a sock, stocking or handkerchief. ${ }^{43}$ When implemented as blanket precautions, rather than protecting patients and staff, they could hinder patients' self-confidence, self-esteem and (re)building of healthy social relationships necessary for achieving the best possible quality of life, whether inside or outside the asylum. The Board, however, supported many of these practices, erring on the side of caution, even though, for some patients, this contradicted its stated objective of providing as near normal a life as possible.

The authorities were alert to the problem that abuse and injury was not all one-way, and that, from time to time, staff sustained injuries at the hands of patients. ${ }^{44}$ Most injuries to staff were minor but occasionally they could be life threatening, news of which sometimes reached the local or national press. ${ }^{45}$ Newspaper reports could reinforce and perpetuate stereotypes of dangerous lunatics who needed to be confined to asylums, alongside gratitude and admiration of the asylums and their dedicated staff who endured such treatment. Some staff lost their jobs following injury, such as a probationer nurse who sustained a detached retina after being hit by a patient because "the loss of sight to an eye precludes the employee from being an efficient nurse". ${ }^{46}$ Another nurse was too nervous to return to work after a patient injured her ear. She sought compensation, for which the asylum was liable under the Workmen's Compensation Act 1897. ${ }^{47}$ No details are given of the ear injury, but "compensation neurosis" or "trauma neurosis", was recognised pre-war, including minor physical injury triggering mental symptoms which recovered on securing a financial settlement. ${ }^{48}$ In contrast, the psychological consequences of physical abuse of patients appeared to be disregarded.

Louise Hide commented that it was impossible to quantify how often physical altercations occurred on the wards, among patients, between patients and staff, and among staff. Minor incidents which were resolved at ward level were unlikely to reach the ears of the $\mathrm{VC}$, let alone the Board. ${ }^{49}$ Nevertheless, the Board admitted to having to deal with allegations of brutality inflicted by attendants "almost daily and sometimes had to prosecute." 50 This comment was made in the context of the Board's response to concerns about asylums practices which Leonard Winter, a temporary wartime attendant, had raised with the Society of Friends and 
the National Council for Lunacy Reform. The response indicated that the Board knew about ill-treatment and that it proposed disciplinary measures, a "bad apple" approach, removing individual staff who were considered undesirable in order to prevent spread of sub-standard practice to others.

Brutality towards vulnerable individuals was (and is) never acceptable, but if "almost daily" meant five times in a working week, that amounted to 250 incidents a year known to the Board affecting an asylum patient population of 100,000 . This estimate may be the tip of the iceberg, but it also fits with anecdotal evidence given by former patients to the Cobb Inquiry into asylum practices. They described their attendants' behaviours in a variety of ways which suggest that physical abuse was neither an inevitable nor daily part of a patient's asylum experience. One patient recalled that he "never saw the attendants use more force on a man than was absolutely necessary for the way the man was acting". 51 Another described them as "decent Englishmen who do their best for everybody". ${ }^{52}$ Others noted variable degrees of benevolence:

some I found good,...did what they thought best for the patients; they are the salt of the institution. Then there is a second class who...do as little work as possible and do anything to make it a comfortable job....And the third class, who are frankly brutal. 53

The middle group were the majority, more likely to demonstrate "indifference and callousness" rather than malice. ${ }^{54}$ Overall, it appears reasonable to conclude that most patients were not physically victims of brutality most of the time. However, it is harder to be conclusive about the extent of the emotional harm caused to them by experiencing, witnessing or hearing about abuse. It is still harder to determine the frequency of non-physical bullying and infringements of human dignity, such as bad language from staff ("I heard more filthy language in the asylum than in the slums of Liverpool and London"55). Bad language was unlikely to have been used in the presence of seniors and left no visible scratches or bruises. 


\section{Broken Bones and CAULIFLOWER EARS: FACTS AND FICTIONS}

In the contested narrative of harm to patients and the reputation of asylums, theories of fragile bones, haematoma auris (popularly termed "cauliflower ear") and status lymphaticus (discussed in Chapter 3) emerged to explain injury and sudden death. For two of the conditions, Latin names added authority; fragile bones did not acquire one, probably because "fragilitas ossium" was already used to describe a hereditary syndrome which presented in childhood. ${ }^{56}$ Injuries sustained by patients demanded explanations which, from the perspective of staff and leadership, preferably laid the responsibility for them on patients rather than staff. Scientific theories assisted with this.

Emerging concepts of accident proneness and hypotheses that insane patients had generally fragile bones gained ground in the late nineteenth century, helping to deflect blame from staff accused of heavy-handed restraint or deliberate injury to patients. ${ }^{57}$ Well-reasoned explanations, at a time of enthusiasm about scientific medical breakthroughs, could convince professionals and public. The fragile bone hypothesis was timely, coinciding with other discoveries about bone abnormalities, such as the effects of poor diet and lack of sunshine, ${ }^{58}$ but distinguishing between science and supposition was tricky, partly due to research and statistical methodology. Not all authorities concurred that asylum patients had fragile bones. ${ }^{59}$ Charles Macnamara, a medically qualified polymath writing in the late nineteenth and early twentieth centuries, was unconvinced by fragile bone theories accounting for injuries. His investigations into bone strength failed to identify anything to support increased fragility compared to sane people of the same age:

It seems to me more probable that when several of the ribs are found to be fractured during life, or after death, in the case of lunatics, it is not impossible that the injury has been caused by the attendants kneeling on the patients' chests to keep them from moving [and it was] just as likely to happen...to a person in sound health as to one in an insane condition. ${ }^{60}$

Psychiatrist Lionel Weatherly also expressed scepticism of the fragility hypothesis alongside outrage about insufficient penalties imposed on attendants found to have broken a patient's ribs. He remarked scathingly: "We have Societies for the protection of children, cats, dogs and horses; 
they are sent to prison. We find an attendant is fined $£ 2$ for breaking the ribs of a patient". ${ }^{61}$ One late-nineteenth century newspaper report proposed that, in the absence of direct evidence of any other cause, asylum deaths associated with rib fractures should incur an automatic manslaughter charge against the attendant. ${ }^{62}$ Jennifer Wallis commented that the Scottish physician, William Lauder Lindsay, argued that the disappearance of mechanical means of restraint during the nineteenth century had increased the risk of injury due to attendants single-handedly trying to restrain patients or convey them into a seclusion room. ${ }^{63}$ Lauder's conclusion was cited by a colleague in France: "if England is the country of non-restraint, it is also the country of broken ribs". ${ }^{64}$

Regarding training for medical students and doctors in the subject of fractures and other injuries associated with insanity, one textbook of psychiatry which discussed physical conditions to which insane people were considered liable, mentioned neither fragile bones nor haematoma auris. ${ }^{65}$ Similarly, some general textbooks of medicine and surgery did not mention them. ${ }^{66}$ Other textbooks, such as Norman Barnett's surgical compendium, warned that "Lunatics are subject to fractures without marked cause, attendants often being wrongly blamed for having caused them." It gave reasons why asylum patients might have fragile bones, such as tuberculosis and syphilis. ${ }^{67}$ However, neither caused generally fragile bones, and their circumscribed lesions were rare in ribs and would have been detectable at post-mortem. ${ }^{68}$ Overall, there is little evidence that tuberculosis or syphilis would have accounted for the frequency of fractures. ${ }^{69}$ Later, Edward Hare, a mid-twentieth century psychiatrist, recalled his experience of working with patients with brain syphilis (general paralysis of the insane, GPI): he "never met one with fractured ribs and [did not] recall reading or being told that this was a complication to be looked for."70 If rib fractures were even a rare direct complication of GPI, it is likely that some echoes of them would have continued to appear in textbooks as something about which practitioners should be aware. More likely, GPI caused disturbed behaviours which made the patient liable to excessive force which was used punitively or during manual restraint by insufficiently trained and exasperated staff.

It is hard to believe that the deaths of Henry M at Portsmouth Asylum, attributed to a fracture of the wrist, or of Lucy R at Bristol, with a fractured forearm following a struggle with a nurse, told the whole story. ${ }^{71}$ These relatively minor injuries were unlikely to have been fatal, unless complications ensued, such as untreatable infection. Should that have 
happened, it is likely that staff or VCs would have referred to it as an exonerating factor. The practice of not informing the asylum doctor about an altercation soon after it happened, plus reduced numbers of postmortems during the war, may have resulted in only obvious injuries being recorded and more serious internal injuries remaining undetected. The fragility hypothesis allowed VCs to acknowledge that struggles took place between patients and staff, but to draw the conclusion that injury was due to physical vulnerability associated with insanity, and that the force used was appropriate to the degree of disturbed behaviour caused by their mental state. ${ }^{72}$ The Board probably over-trusted VCs' analyses about injuries and failed to probe objectively. If a VC set out a convincing case, coroners tended to concur, recording a verdict of death by misadventure rather than manslaughter. ${ }^{73}$

Haematoma auris was another condition directly attributed to insanity. As Russell Barton, a medical superintendent in the 1960s, described:

when I introduced the course for senior charge nurses I explained to them the curious condition known as auris haematoma, which was a big red swelling of the ear which usually occurred a little while before the patient died, and it was thought to be the blood pushed out of the brain. And so I explained this...

the big market where they sold cattle and stuff. You see when they move a calf from one stall to another - 'e don't go calm like! So ya' grab 'im ba' the ears and ya pull 'is tail and then e's gotta go where ya' push 'im - and 'e does!

And of course it immediately rang a bell. ${ }^{74}$

Haematoma auris occurred more commonly on the left than the right, suggesting that it was caused by the right hand of a person facing the patient and giving a blow, or using that hand to lead them by the ear. Hare explained that the disorder was most common in patients with the most disturbed behaviours. He referred to one asylum where attendants were held responsible for it and the condition disappeared. ${ }^{75}$

True accidents could happen, manual handling of patients could be inadvertently harsh, but excessive force could also be applied deliberately, disproportionate to the patient's needs. Too often the leadership turned a blind eye to the possibility of malicious injury. Medical-scientific explanations attributing injury to a patient's inherent predisposition were acceptable to public and professionals and allowed the asylum leadership to exonerate staff, reassure the public of the adequacy of the care 
provided, and preserve the reputation of their institution, even when treatment was detrimental to the patients. ${ }^{76}$

\section{ESCAPES}

Patients discussed how to escape from asylums. At Hanwell, rumours were rife that the easiest way was to take advantage of low lighting levels at night while the main door was unlocked in order to enable evacuation in the event of a direct hit in an air raid. Only one patient, Alice B, was reported to have escaped this way, almost two years after the unlocked door policy began. ${ }^{77}$ Montagu Lomax discussed issues around escape and patients' freedom of movement, noting that in some mental hospitals in other countries, many patients had "parole" of the grounds. Patients with parole seldom abused the privilege and, as at Hanwell, unlocked doors did not equate with attempted mass exodus. Lomax argued that the freedom of parole was "a restorer of hope and self-confidence to minds sadly in need of both" and that "It is not those patients who are most trusted who attempt to escape, it is those who despair of ever getting out, and who are reckless in consequence." 78 Lomax agreed with Mary Riggall, that patients on parole felt their discharge imminent so did not want to endanger its realization. In her own case, she was aware that any actions deemed misbehaviour could be misconstrued as part of her insanity and jeopardise her discharge, so she decided against trying to escape. ${ }^{79}$

The term "escape" was used in the Lunacy Act 1890 which stipulated:

If any manager, officer, or servant of an institution for lunatics wilfully permits, or assists, or connives at the escape or attempted escape of a patient, or secretes a patient, he shall for every offence be liable to a penalty not exceeding twenty pounds nor less than two pounds. ${ }^{80}$

The Act also required an asylum to search for its missing patient for 14 days, after which time, if still at liberty, the patient was declared not insane and could no longer be detained under the original order. ${ }^{81}$ Without outside help, such as advice, plans or money, ${ }^{82}$ dressed in asylum clothes, almost penniless, and miles from home, a successful escape suggested that the patient was desperate alongside having courage, ingenuity and organisational skills. One patient climbed down a ward stack-pipe after throwing his bundle of clothes outside, another removed a window pane and lowered himself to the ground on knotted sheets. ${ }^{83}$ 
Mr. K helped his wife Elizabeth to escape, by walking out from Colney Hatch with her at the end of visiting time. He posted her asylum-owned clothes back to the asylum from Peterborough, with an address-less covering note explaining that she was doing well. ${ }^{84}$ Possibly inspired by Elizabeth's success, two months later, Bertha B absconded with her visitor. She too went to a secret location. ${ }^{85}$

Some escapees were "recaptured", a word usually applied to criminals or animals, with language reinforcing notions that patients were dangerous. ${ }^{86}$ Napsbury noted that of its eight escapees in 1914, four were recaptured within the 14 -day time limit. ${ }^{87}$ Often, a local person, sometimes a child, brought them back. Local people accepted the patients as needing help, although the expectation of a half-a-crown $\left(12 \frac{1}{2} \mathrm{p}\right)$ reward might have encouraged them to assist. A sympathetic local acceptance of asylum patients was inconsistent with a more negative wider public understanding about them. VCs, however, had different concerns when patients escaped: one VC was less bothered about the escapee's wellbeing than about the asylum clothing he wore at the time, listing each item, including under-garments, which would have to be replaced. ${ }^{88}$

Escapes from asylums were uncommon, the Board's data indicating that a dozen or so of 100,000 detained patients escaped each week. ${ }^{89}$ During the war, one medical superintendent commented that it was "extraordinary that accidents and escapes are so few in number seeing that our temporary staff are by no means in the prime of life, many in fact are elderly". ${ }^{90}$ In addition to using the term "accidents" to mean "injuries" which the authorities deemed to be accidental, the statement indicated that asylums preferred to employ younger staff, partly because of their physical abilities. This gives insight into the leadership's perceptions of acceptable ways of managing disruptive patients. The possibility that older male staff, or women nurses working on male wards, could use non-physical methods successfully to manage disturbed patients, received little consideration. Neither did the low rate of escapes prompt an honest review of the feasibility of unlocking more doors. In the conservative and risk-averse culture of the asylum leadership, the easiest course was to not ask too many questions or make suggestions which might rock the boat. Occasionally, an escape ended in suicide, ${ }^{91}$ an outcome which the authorities could use to further justify their caution. 


\section{SUICIDES}

Before the war, the suicide rate for England and Wales was approximately one in 10,000 of the general population (all ages), about 3500 people a year. ${ }^{92}$ In 1914, of around 100,000 patients certified under the Lunacy Act, there were 34 suicides nationally, about three in $10,000 .^{93}$ Twelve of these took place after certification, mainly in workhouse infirmaries, before transfer to an asylum. ${ }^{94}$ Two occurred when on trial leave and two after escape, leaving 18 who were patients within the asylums at the time, ${ }^{95}$ a figure little more than in the general population outside.

If asylum suicide rates were as low as reported, we need to understand how people of high risk of suicide were managed in the asylums. Anne Shepherd and David Wright's study of two asylums to the west of London revealed that between one quarter and one third of patients were classified as suicidal on admission. Vigilance was the main treatment, or sedation, particularly in understaffed asylums. ${ }^{96}$ Mercier advised that "a suicidal patient must never be allowed out of sight" although the Board disputed this, recognising that a balance had to be achieved as constant supervision could also be detrimental to recovery. ${ }^{97}$ Some of the practical aspects of observing patients were discussed in Chapter 6, such as the absence of doors on lavatories. However, to facilitate observation, adequate communication between staff was essential, as in the case of Mrs. I. To this end, asylums were expected to implement a standard procedure. Each "suicidally disposed patient" would have a separate "caution parchment" which the staff member responsible for observing the patient was expected to read, understand and sign, handing it on to the colleague taking over at the end of the shift or if the patient was moved to another location. ${ }^{98}$ Textbooks also provided valid advice: if the patient was melancholic, "Favourite hours for suicides to make their attempts are the early hours" 99 and "the experienced nurse is always suspicious of the happy smiling face that conceals a heavy heart. Be especially watchful over such patients and also over convalescent patients". ${ }^{100}$

Suicide and "attempted suicide" were criminal acts until 1961. ${ }^{101}$ This legal status could lead to concealment of the act, which could not only affect statistics, but more importantly would impact on the help sought by and offered to distressed and despairing people. The criminal designation of attempted suicide meant that the Home Office delegated to the police the responsibility for ensuring that the offence was not repeated. The police did not want this responsibility and considered it a medical duty; 
the asylums did not want the person if they had physical injuries; neither did the general hospitals, on the grounds that they lacked the skills to calm a disturbed patient. These disputes about responsibility overlapped with financial concerns, as close observation was also costly. ${ }^{102}$ Each organisation tried to pass the buck and responded in a way which was detrimental to the wellbeing of the troubled human being who required help.

In contrast to the police view, William Norwood East, a forensic psychiatrist during the war years, regarded conviction for attempted suicide as an effective way to secure appropriate treatment: for people not sufficiently insane to be certified, a prison hospital could provide rest, good food, quiet, and medical attention. It also provided a fixed period of detention, unlike Lunacy Act certification which risked an indeterminate period in an asylum. Once a prisoner, a second court appearance would precede release, allowing review of the situation. Another advantage was that more philanthropic resources were available to criminals released from prisons than lunatics discharged from asylums, including material assistance and help to secure employment. ${ }^{103}$ This philanthropic provision fitted with Jose Harris's analysis that "late Victorian lower classes preferred to be thought bad rather than mad", ${ }^{104}$ and that for the suicidal person and his family, a criminal record balanced favourably against the stain of lunacy certification. According to East, very few of those convicted returned except for malingerers and alcoholics, suggesting successful interventions, although other outcomes, such as suicide or death from other causes, rather than improvement in mental wellbeing, could have contributed to his statistics. ${ }^{105}$

The rehabilitative role of prison hospitals, as East advised, was compatible with other theories, notably those of Émile Durkheim who viewed suicide as a social, rather than psychiatric issue. Durkheim was reluctant to accept psychiatrists' claims that most instances of suicide were a consequence of insanity, an opinion based on their experience in the asylums with limited professional responsibilities in the wider community. ${ }^{106}$ Durkheim regarded suicide as a social phenomenon, due to the interaction between the actor and society. He argued that each society had a collective inclination towards suicide and that, despite looking like a highly individual and personal phenomenon, suicide was explicable through social structures and functions. ${ }^{107}$ This hypothesis fitted with lower suicide rates internationally during the war, a time of intense emotional pressure together with greater social cohesion. ${ }^{108}$ 
Although in the community attempted or successful suicide was designated a criminal act, within the asylum the rule of law focused on staff in immediate charge of the patient. ${ }^{109}$ For those staff, William Stoddart spelt out a terrifying image of the worst scenario:

a suicide in an asylum is regarded throughout the lunacy world as more or less of a disgrace, and the staff of a particular institution is in a state of depression and anxiety for days or weeks after the occurrence, even among those who did not know the patient. [Should a member of staff's] carelessness lead to such a catastrophe.... [he] is discharged from the asylum without a character and reported to the Board of Control, which enters his name in a black book, so that he may never more be engaged in mental nursing, and he is prosecuted in a court of law for criminal carelessness, and may be sentenced to a term of imprisonment. ${ }^{110}$

In contrast, even when a VC failed to implement the Board's safety recommendations to prevent suicide, ${ }^{111}$ the leadership was not implicated directly or likely to be prosecuted. The onus fell on the staff of the lowest ranks who interacted with the patients face to face.

\section{CONCLUSIONS}

Ward staff were undervalued as individuals, paid at the level of unskilled workers and had little training in therapeutic methods. They were expected to work in a pressurised and stressful, overcrowded and understaffed, almost impossible situation, under an authoritarian regime where seniority was seen to equate with superior personal attributes. The style of leadership induced distrust between lower ranks of the workforce and their masters who also had the right to dismiss them summarily, for disobedient, or otherwise aberrant, behaviours. These systemic tensions prohibited lower ranks from verbalising their workplace difficulties to those in authority. If work became intolerable, the emotional fragility, vulnerability and frustration of staff could be expressed physically, typically against those with even less power than they themselves had. Expressing one's emotions in this way has acquired different labels at various times, from "kicking the cat" to "Munchausen's by proxy" and "displaced aggression".

According to Lomax, attendants failed to make patients their prime concern: 
It is the injury to themselves that most attendants are thinking of, much more than the possible injury to the patient....I don't suppose an attendant really cares twopence if a lunatic commits suicide or escapes, provided the blame for either cannot be brought home to himself. ${ }^{112}$

Within the asylum's hierarchical management structure, staff at the same level would rely on each other for support, including concealing, and thus perpetuating, each other's misdemeanours. The Board indicated that it knew about asylum rough handling, but apart from taking disciplinary measures it did not identify systemic problems which might require attention. Punishment of staff was used as a deterrent and to weed out supposedly "bad apples" to prevent contamination of the batch. The "resignation" or dismissal of the accused staff member appeared to satisfy the Board that the VC had done its duty, and the Board did not probe matters further. ${ }^{113}$

The asylum leadership demonstrated to staff that harsh and punitive methods were acceptable to control people considered to be of lower status if their actions deviated from what was expected. Rigid discipline, obedience and punishments, may have been exaggerated during the war, reflecting a more military style leadership. However, military methods which fostered discipline and taught aggressive tactics were unlikely to nurture kindness, emotional support and respect of the sort required in healthcare institutions with the objectives of providing, in the words of the Lunacy Act, "care and treatment". The Board, like the VCs, did not link harsh practices to their own authoritarian management style, but at its worst, the patients and ward staff had to cope with a punitive system characterised by a sanctimonious leadership, dysfunctional communication, distrust, dishonesty, secrecy and fear.

\section{Notes}

1. Charles Mercier, The Attendant's Companion: A Manual of the Duties of Attendants in Lunatic Asylums (London: J and A Churchill, 1898), 72.

2. Mercier, Attendant's Companion, 3.

3. Mercier, Attendant's Companion, 31.

4. Committee on the Administration of Public Mental Hospitals (Chairman: Sir Cyril Cobb) (Cobb Inquiry), 15 March 1922 AM Donaldson Q:607, MH 58/219 TNA; Louise Hide, Gender and Class 
in English Asylums 1890-1914 (Basingstoke: Palgrave Macmillan, 2014), 158 .

5. Cobb Inquiry, 15 March 1922 Mr. Cox Q:403, 408, 413, MH 58/219 TNA.

6. Cobb Inquiry, 15 March 1922 AM Donaldson Q:614, 640-42, MH $58 / 219$ TNA.

7. Rachel Grant-Smith, The Experiences of an Asylum Patient (London: George Allen and Unwin Ltd, 1922), 85.

8. Grant-Smith, Experiences, 85.

9. Grant-Smith, Experiences, 9.

10. Colney Hatch LCC/MIN/01006 Meeting, 13 July 1916, 207-8 LMA.

11. Colney Hatch LCC/MIN/01007 Meeting, 9 August 1918, 131 LMA.

12. Russell Barton, "Foreword," ix-xi, in Barbara Robb, Sans Everything: $A$ Case to Answer (London: Nelson, 1967).

13. Colney Hatch $\mathrm{H} 12 / \mathrm{CH} / \mathrm{B} / 18 / 003$ Photographs of female patients admitted and discharged 1908-1918 LMA; Census 1911 https://www. ancestry.co.uk/cs/uk191lcensus.

14. Colney Hatch LCC/PH/MENT/04/016 Lists of patients admitted, died and recommended for discharge, 1911-1917 LMA.

15. Colney Hatch $\mathrm{H} 12 / \mathrm{CH} / \mathrm{B} / 16 / 012$ Case notes of female patients who died in 1933-1934 LMA.

16. Hide, Gender and Class, 158; Erving Goffman, Asylums: Essays on the Social Situation of Mental Patients and other Inmates (1961; Harmondsworth: Penguin, 1980), 99.

17. Colney Hatch LCC/MIN/01005 Meeting, 24 May 1916, 103-4 LMA. 18. Colney Hatch LCC/MIN/01006 Meeting, 18 May 1917, 179 LMA.

19. Hanwell LCC/MIN/01096 Meeting, 26 February 1917, 324-25 LMA.

20. Hanwell LCC/MIN/01093 Meeting, 27 April 1914, 189-90; Colney Hatch LCC/MIN/01003 Meeting, 4 December 1914, 198 LMA.

21. Mercier, Attendant's Companion, 2.

22. Anon. "London Gossip," North-Eastern Daily Gazette (Middlesbrough, England), 3 March 1887.

23. Colney Hatch LCC/MIN/01001 Meeting, 7 November 1913, 309-10 LMA.

24. Colney Hatch LCC/MIN/01002 Meeting, 21 November 1913, 12 LMA.

25. Hanwell LCC/MIN/01093 Meeting, 6 July 307-8 LMA.

26. Hanwell LCC/MIN/01094 Meetings: 20 July 1914, 10; 14 September 1914, 59-60 LMA.

27. John Collie and Arthur Spicer, Malingering and Feigned Sickness (London: E Arnold, 1913); Hanwell LCC/MIN/01094 Meeting, 26 October 1914, 103-4 LMA. 
28. First Annual Report of the Board of Control, for the Year 1914 (London: HMSO, 1916) (BoC AR 1914), Part 1, 28.

29. Colney Hatch LCC/MIN/01001 Meeting, 9 May 1913, 75-79 LMA.

30. Lunacy Act 1890 sections 322-24; BoC W/FM 17 March 1920, 80 MH 50/48 TNA.

31. Lunacy Act 1890 section 322.

32. Colney Hatch $\mathrm{H} 12 / \mathrm{CH} / \mathrm{C} / 04 / 004$ Male attendants' wages book 1917-1918 LMA.

33. Mercier, Attendant's Companion, 124.

34. Mercier, Attendant's Companion, 1.

35. Montagu Lomax, The Experiences of an Asylum Doctor (London: Allen and Unwin, 1921), 89.

36. Fifth Annual Report of the Board of Control, for the Year 1918 (London: HMSO, 1919), 29, 31.

37. Cobb Inquiry, "Reports of Visits to Mental Institutions: Mrs. Munn," 1922, MH 58/221 TNA.

38. Civil Registration Death Index, England and Wales, 1916-2007, https://www.ancestry.co.uk/search/collections/onsdeath93/.

39. Colney Hatch LCC/MIN/01005 Meeting, 14 July 1916, 218 LMA.

40. Cobb Inquiry, 16 February 1922 Mr. Trevor Q:1, MH 58/219 TNA.

41. Mercier, Attendant's Companion, 23-24; BoC W/FM 29 August 1917, $253 \mathrm{MH}$ 50/45 TNA.

42. Mercier, Attendant's Companion, 12.

43. Mercier, Attendant's Companion, 24; Jane Hamlett and Lesley Hoskins, "Comfort in Small Things? Clothing, Control and Agency in County Lunatic Asylums in Nineteenth- and Early Twentieth-Century England,” Journal of Victorian Culture 18 (2013): 93-114, 105.

44. BoC AR 1914, Part 2, Kesteven Asylum 27 January 1914, 262.

45. Anon. "A Homicidal Attack on Dr Hetherington, Medical Superintendent, District Lunatic Asylum, London-Derry," Journal of Mental Science (JMS) 61 (1915): 169, citing Belfast Evening Telegraph 26 November 1914.

46. LCC LCC/MIN/00584 Meeting, 26 November 1918, 98 LMA.

47. LCC LCC/MIN/00583 Meeting, 14 May 1918, 572 LMA.

48. William Thorburn, "The Traumatic Neuroses," Proceedings of the Royal Society of Medicine 11 (1914): Neurological Section, 1-14; Ryan Hall and Richard Hall, "Compensation Neurosis: A Too Quickly Forgotten Concept?" Journal of the American Academy of Psychiatry and the Law 40 (2012): 390-98.

49. Hide, Gender and Class, 157.

50. National Council for Lunacy Reform, minute book 1920-1921, 30 September 1920, Report of Mr. Parley, SA/MIN/A/1 WL.

51. Cobb Inquiry, 15 March 1922 Mr. Sale Q:693, MH 58/219 TNA. 
52. Cobb Inquiry, 16 March 1922 Charles McCarthy Q:825, MH 58/219 TNA.

53. Cobb Inquiry, 30 March 1922 Edward Mason Q:2027, 2040, MH 58/220 TNA.

54. Cobb Inquiry: 30 March 1922 Edward Mason Q:2050; 6 April 1922 WH Skevington Q:2666, MH 58/220 TNA.

55. Cobb Inquiry, 30 March 1922 Edward Mason Q:2055, MH 58/220 TNA.

56. Anon. "Fragilitas Ossium (Osteopsathyrosis)," Lancet 13 December 1902, 1645-46; Russell Howard, The Practice of Surgery (London: Edward Arnold, 1914), 516-17.

57. Jennifer Wallis, Investigating the Body in the Victorian Asylum: Doctors Patients and Practices (London: Palgrave Macmillan, 2017), 101-30; SWD Williams, "On Fractured Ribs in the Insane," Lancet 3 September $1870,323-24$.

58. Theobald Palm, "Etiology of Rickets," BMJ 1 December 1888, 1247.

59. Wallis, Investigating the Body, 102-3; Anon. "A Death in a Lunatic Asylum," Lancet 8 January 1870, 58.

60. Charles Macnamara, Lectures on Diseases of Bones and Joints (London: J and A Churchill, 1887), 253.

61. Cobb Inquiry, 24 March 1922 Lionel Weatherly Q:1672, MH 58/219 TNA.

62. Anon. "London Gossip."

63. See Chapter 3 for discussion on different methods of restraint; also, Wallis, Investigating the Body, 105.

64. William Lauder Lindsay, cited in T Christian, "On the Alleged Fragility of the Bones of General Paralytics," JMS 31 (1886): 453-59, 457-58.

65. William Stoddart, Mind and Its Disorders (London: HK Lewis, 1908), $421-31$.

66. e.g. William Osler, The Principles and Practice of Medicine (London and New York: Appleton, 1912).

67. H Norman Barnett, The Student's Textbook of Surgery (London: Heinemann, 1916), 200.

68. A King and R Catterall, "Syphilis of Bones," British Journal of Venereal Diseases 35 (1959): 116-28; James Miller, Practical Pathology Including Morbid Anatomy and Post-Mortem Technique (London: Adam and Charles Black, 1914), 260.

69. E.g. Hanwell HIl/HLL/B/31/006 Post-mortem register, males, 1915-1917 LMA.

70. Edward Hare, "Old Familiar Faces: Some Aspects of the Asylum Era in Britain," 82-100, in Lectures in the History of Psychiatry, ed. Robin Murray and Trevor Turner (London: Gaskell, 1990), 90. 
71. BoC W/FM 1 April 1914, 4; 3 June 1914, 81; 23 December 1914, 286 MH 50/43 TNA.

72. BoC AR 1914, Part 2, Derbyshire Asylum 8 July 1914, 216.

73. Hare, "Old Familiar Faces": 90; Colney Hatch LCC/MIN/01007 Meeting, 9 August 1918, 131 LMA.

74. Russell Barton, Oral history interview by Diana Gittins GC/244/2/19, 54 WL.

75. Hare, “Old Familiar Faces": 86.

76. W Sullivan, "Haematoma Auris in the Insane," JMS 53 (1907): 192-93.

77. Hanwell LCC/MIN/01097 Meeting, 13 March 1917, 11 LMA.

78. Lomax, Experiences, 224-25.

79. Mary Riggall, Reminiscences of a Stay in a Mental Hospital (London: Arthur Stockwell, 1929), 15.

80. Lunacy Act 1890 section 323.

81. Lunacy Act 1890 section 85.

82. Lomax, Experiences, 67, 69.

83. Colney Hatch LCC/MIN/01001 Meeting, 29 August 1913, 214; LCC/MIN/01002 Meeting, 24 April 1914, 213 LMA.

84. Colney Hatch LCC/MIN/01003 Meeting, 15 January 1915, 238-39 LMA.

85. Colney Hatch LCC/MIN/01004 Meeting, 12 March 1915, 7; 26 March 1915, 31 LMA.

86. E.g. Hanwell LCC/MIN/01096 Meeting, 29 January 1917, 297 LMA.

87. Napsbury H50/A/01/024 Meeting, 22 May 1915, 12 LMA.

88. Colney Hatch LCC/MIN/01005 Meeting, 25 February 1916, 90 LMA.

89. BoC W/FM, reported at each meeting, $\mathrm{MH} 50 / 43-48$ TNA.

90. Hanwell LCC/MIN/01097 Meeting, 16 July 1917, 135 LMA.

91. BoC W/FM 23 December 1914, 286 MH 50/43 TNA.

92. W Norwood East, "On Attempted Suicide, with an Analysis of 1000 Consecutive Cases" JMS 59 (1913): 428-78, 434.

93. BoC AR 1914, Part 1, 27.

94. BoC AR 1914, Part 2, Durham Asylum 8 May 1914, 223.

95. BoC AR 1914, Part 1, 27.

96. Anne Shepherd and David Wright, "Madness, Suicide and the Victorian Asylum: Attempted Self-Murder in the Age of Non-Restraint," Medical History 46 (2002): 175-96, 193.

97. Mercier, Attendant's Companion, 6; Fourth Annual Report of the Board of Control, for the Year 1917 (London: HMSO, 1918), 37.

98. BoC AR 1914, Part 2, Lancaster Asylum 22 July 1914, 247; Mercier, Attendant's Companion, 22.

99. Mercier, Attendant's Companion, 10. 
100. William Stoddart, Mental Nursing (London: Scientific Press Ltd, 1916), 31.

101. Until the Suicide Act 1961 (England and Wales).

102. Christopher Millard, "Re-inventing the 'Cry for Help': 'Attempted Suicide' in Britain in the Mid-Twentieth Century c.1937-1969" (PhD thesis, Queen Mary University of London, 2012) 46-48.

103. East, "Attempted suicide": 430-31.

104. Jose Harris, Private Lives, Public Spirit: A Social History of Britain 18701914 (Oxford: Oxford University Press, 1993), 57.

105. East, "Attempted Suicide": 430-31.

106. Émile Durkheim, Suicide. A Study in Sociology (tr. John Spaulding and George Simpson) (London: Routledge and Kegan Paul, 1979), 62.

107. George Simpson, "Introduction," 13-32, in Durkheim, Suicide, 16.

108. Maurice Halbwachs, The Causes of Suicide (tr. Harold Goldblatt) (1930; London: Routledge and Kegan Paul, 1978), 213-14.

109. Lunacy Act 1890 sections 322-24.

110. Stoddart, Mental Nursing, 27.

111. BoC AR 1914, Part 1, 27; Part 2, Salop Asylum 8 July 1914, 297.

112. Lomax, Experiences, 89.

113. E.g. BoC W/FM 14 October 1914, 209 MH 50/42 TNA.

Open Access This chapter is licensed under the terms of the Creative Commons Attribution 4.0 International License (http://creativecommons.org/licenses/ by $/ 4.0 /$ ), which permits use, sharing, adaptation, distribution and reproduction in any medium or format, as long as you give appropriate credit to the original author(s) and the source, provide a link to the Creative Commons license and indicate if changes were made.

The images or other third party material in this chapter are included in the chapter's Creative Commons license, unless indicated otherwise in a credit line to the material. If material is not included in the chapter's Creative Commons license and your intended use is not permitted by statutory regulation or exceeds the permitted use, you will need to obtain permission directly from the copyright holder.

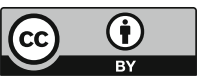

